\title{
Una dosis de nevirapina asociada a la profilaxis con zidovudina reduce la transmisión vertical del VIH.
}

\section{Objetivo}

Evaluar la seguridad y la eficacia de una dosis única de nevirapina administrada a mujeres embarazadas en el momento del trabajo de parto y a los recién nacidos, adicionalmente a la profilaxis con zidovudina, para la prevención de la transmisión vertical del VIH.

\section{Diseño}

Ensayo clínico multicéntrico, de Fase $\mathrm{III}^{*}$, aleatorizado, controlado con placebo.

\section{Lugar}

Estudio realizado en 37 centros de Tailandia en colaboración con el Ministerio de Salud Pública de Tailandia y la Escuela de Salud Pública de Harvard, Boston (EEUU).

\section{Pacientes}

Mujeres embarazadas con infección por VIH documentada que recibían la profilaxis habitual con zidovudina (300 mg cada $12 \mathrm{hs}$ ) a partir de la semana 28 de gestación, y recibiendo zidovudina por al menos 2 semanas previas a la asignación.

\section{Intervención}

Se establecieron tres grupos de tratamiento: Nevirapina-nevirapina (administración a la madre y al recién nacido), Placebo-placebo, y Nevirapina-Placebo (administración solo a la madre)

Luego del primer análisis interino, el Comité independiente de monitoreo de datos y seguridad recomendó la suspensión del grupo Placebo-placebo.

\section{Medición de resultados principales}

Detección de infección por $\mathrm{VIH}$ en recién nacidos mediante Reacción en cadena de la Polimerasa (PCR) en el momento del nacimiento, a las 6 semanas, 4 y 6 meses de edad.

\section{Resultados principales}

De 1844 pacientes aleatorizadas, 1807 fueron seguidas hasta el parto.Análisis interino y final: ver tabla. No se observaron erupciones cutáneas severas, sólo leves en $3,8 \%$ de las madres y $15,9 \%$ de los niños a los 10 días de vida.

\begin{tabular}{l|c|c|c}
\multicolumn{1}{c|}{ Análisis } & Régimen & $\begin{array}{c}\text { Transmision vertical } \\
\text { (IC 95\%) }\end{array}$ & $\begin{array}{c}\text { NWT\&* }^{*} \\
\text { (IC 95\%) }\end{array}$ \\
\hline Interino & Nevirapin-Nevirapina & $1,1 \%(0,3-2,2)$ & $19(13-42)$ \\
\hline & Nevirapin-Placebo & $2,1 \%(0,6-3,7)$ & $24(14-81)$ \\
\hline Final & Placebo-Placebo & $6,3 \%(3,8-8,9)$ & Referencia \\
\hline & Nevirapin-Nevirapina & $2,0 \%(1,0-3,1)$ & 123 \\
\hline & Nevirapin-Placebo & $2,8 \%(1,6-4,1)$ & Referencia \\
\hline
\end{tabular}

\& Calculado por el Comité editorial

\section{Conclusiones}

El estudio demuestra la eficacia de la adición de nevirapina en monodosis a la madre (o a la madre y al recién nacido) sobre la profilaxis básica con zidovudina en la reducción de la tasa de transmisión vertical de VIH. Si bien se observó una tendencia a favor del grupo Nevirapina-nevirapina sobre el grupo Nevirapina-placebo, no se estableció una diferencia estadísticamente significativa entre estos grupos en el presente estudio.

Fuente de Financiamiento: Subsidio de los Institutos Nacionales de Salud (EEUU), Ministerio de Salud Pública de Tailandia, Boehringer-Ingelheim, GlaxoSmithKline y Roche Molecular Systems.

\section{Comentario}

Este estudio reafirma la noción de que la doble terapia antirretroviral ofrece mejores resultados en la prevención de la transmisión vertical del VIH que el régimen básico de zidovudina del estudio 076 original. ${ }^{1}$ En este contexto la nevirapina se ofrece como un candidato interesante, dado su sinergismo con la zidovudina, su rápida acción antiviral, su perfil de seguridad, y el bajo impacto del costo incremental dada la posibilidad de administración como monodosis.

Esta estrategia de combinación es particularmente relevante para el caso de países en los que se utiliza el régimen profiláctico con zidovudina exclusiva, y de hecho este estudio motivó un cambio en la recomendación del Ministerio de Salud Pública de Tailandia, incorporando una dosis de nevirapina a la madre y al recién nacido como política oficial.

El impacto de estos resultados son seguramente menores en países como el nuestro, en los que no se emplea el régimen de monodroga con zidovudina como estrategia general, sino regímenes combinados de tratamiento. En este sentido, el estudio PACTG $316^{2}$ demostró que el agregado de nevirapina perinatal no ofreció ningún beneficio sobre una terapéutica antirretroviral estándar en mujeres embarazadas con $\mathrm{VIH}$.

Existe además el riesgo del desarrollo de mutaciones virales en una considerable proporción de pacientes, aun con la dosis perinatal de nevirapina, lo cual podría condicionar futuros tratamientos antirretrovirales de la mujer en seguimiento.

Conclusión del comentador:

Lo más razonable para nuestra situación actual, en donde existe disponibilidad gratuita tanto de los tests para diagnóstico de infección por VIH como de la medicación antirretroviral, sería reafirmar la necesidad de la inclusión de análisis para VIH dentro del control prenatal (con consentimiento de la paciente) y la iniciación eventual de un régimen combinado de tratamiento antirretroviral que garantice a la vez la seguridad de la unidad madre-niño y las máximas posibilidades de reducción de la carga viral de la paciente antes del parto.

\section{Dr. Waldo H. Belloso. [ Sección Infectología. Hospital Italiano de Buenos Aires ]}

Belloso, W Una dosis de nevirapina asociada a la profilaxis con zidovudina reduce la transmisión vertical del VIH. Evid. actual. práct. ambul. 2004:7:164 Comentado de:Single-dose perinatal nevirapine plus Standard zidovudine to prevent mother-to child transmission of HIV-1 in Thailand. Lallemant M, Jourdain G, Le Coeur S, y col. N Engl J Med 2004; 351:217-28.

\section{Referencias}

1.Reduction of maternal-infant transmission of human immunodeficiency virus type I with zidovudine treatment. Connor EM, Sperling RS, Gelber RD, y col. N Engl J Med 1994; 331: 117380

2.Two-dose intrapartum/newborn nevirapine and standard antiretroviral therapy to reduce perinatal HIV transmission: a randomized trial. Dorenbaum A, Cunningham CK, Gelber RD, y col. JAMA 2002; 288: 189-98. 